\title{
Rudimentary Myelomeningocele: A Rare Case Report and Literature Review
}

\author{
Gautam $P^{1}$, Goel RG², Kapoor $A K^{3}$, Gupta $\mathrm{SN}^{4}$, Ghimire $\mathrm{PG}^{5}$, Bharti SV
}

\begin{abstract}
Rudimentary meningocele, in which meningothelial elements occupy most of a solid skin-covered mass, is extremely rare. Most reported rudimentary meningocele were on the midline scalp, preferentially involving the occiput and vertex. $A$ 10 yearold child who presented with rudimentary myelomeningocele in the midline at the level of T7-T8 is reported. We believe this is the first reported case of a rudimentary myelomeningocele at this site.
\end{abstract}

Key Words: Child, rudimentary myelomeningocele, thoracic region

\section{INTRODUCTION}

Rudimentary meningocele, a malformation in which meningothelial elements are present in the skin and subcutaneous tissue, has been described under a variety of different terms and has also been referred to as cutaneous meningioma, heterotopic meningothelial hamartoma, sequestrated meningocele, acoelic meningeal hamartoma, and cutaneous heterotopic meningeal nodules ${ }^{1}$.

\section{CASE REPORT}

This 10 years old female child presented to nepalgunj medical college with a mass in her upper back since birth. Physical examination revealed a subcutaneous, firm, painless, noncompressible lump over midline posteriorly (T7-T8 level) measuring $3 \mathrm{~cm}$ in greatest dimension in which the cough impulse was absent. Written consent concerning the operation was obtained from the patient before surgery. The mass was excised with a clinical diagnosis of a "papilloma" and sent for histopathological examination.

\section{PATHOLOGICAL FINDINGS:}

Grossly, an oval, firm polypoidal mass covered with full thickness skin measuring $3 \mathrm{~cm}$ in length, $2.5 \mathrm{~cm}$ in width and 2 $.5 \mathrm{~cm}$ in height. Its cut surface was homogenously solid with a yellow to grey-white color.

1. Dr. Prabesh Gautam

2. Prof. R. G. Goel

3. Prof. A. K. Kapoor

4. Prof. S. N. Gupta

5.Dr. Pragya Gautam Ghimire

6. Dr. Shiv Vansh Bharti

\section{Address for correspondence:}

Dr. Prabesh Gautam

Department of Pathology

Nepalgunj Medical College Teaching Hospital

Kohalpur, Banke, Nepal

E-mail: iamprabesh123@gmail.com

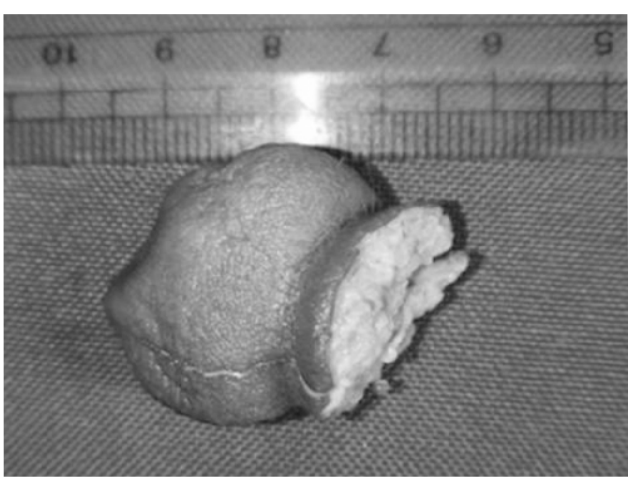

Figure 1. A. Gross photograph of the excised mass with a wide base.

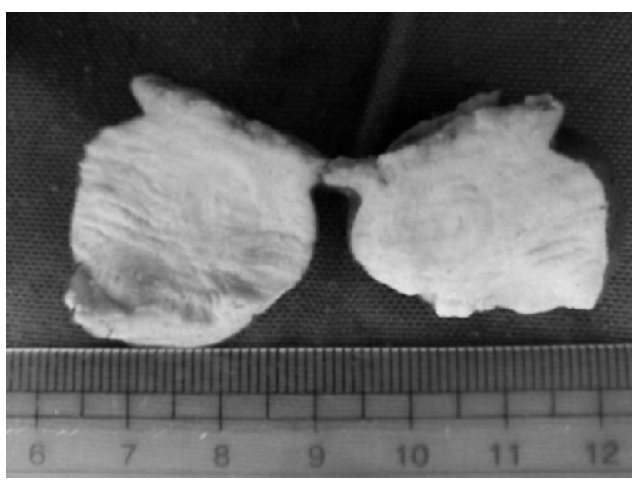

Figure 1. B. Cut surface is homogenously solid with greywhite to yellow color

Microscopically, a poorly circumscribed cutaneous mass covered with epidermis. The mass was made up of pseudovascular spaces and lobules of mature adipocytes in the superficial parts which contrasted with dense collagenous tissue forming whorls containing clusters of meningocytes without atypia, mitosis or necrosis in the deeper parts. Numerous psammomatous calcifications are seen. A focus of well-circumscribed neuroglial tissue was also noted near the deepest resected margin of the mass. 


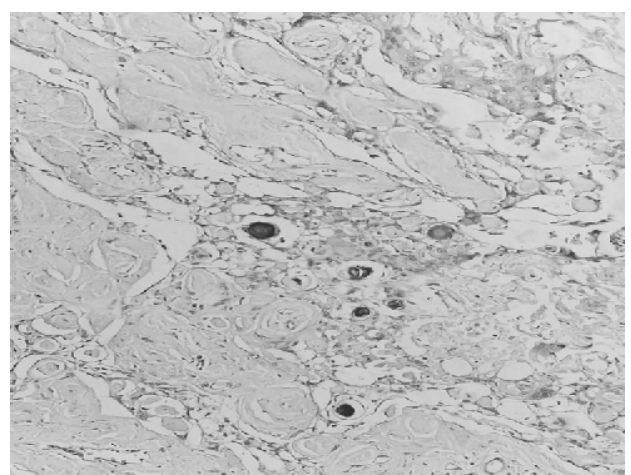

Figure 2A: Low-power magnification shows pseudovascular spaces lined by meningothelial cells and scattered psammomatous calcifications (H\&E ×10)

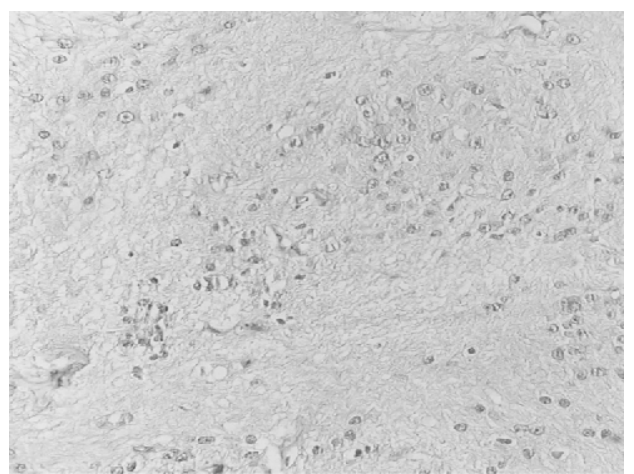

Figure 2B: High power magnification showing neuroglial cells and abundance of neuropil (H\&E $\times 40)$

\section{DISCUSSION}

In 1974, Lopez et al. reviewed the clinicopathological attributes of several meningothelial cutaneous lesions, and adapted the term "acoelic meningeal hamartoma" to describe them indicating that they were thought to be non-neoplastic ${ }^{2}$. Sibley and Cooper $^{3}$ in 1989 represented them as developmental malformations called "Rudimentary meningoceles" (RMs). ${ }^{3}$

Others rendered the same conclusion and preferred the alternative term "meningotheliomatous hamartoma" ${ }^{4}$. While others described it as a "peculiar disease of the skin and subcutaneous fat" ${ }^{5}$.

Reported rudimentary lesions were on the midline scalp, preferentially involving the occiput and vertex ${ }^{1}$. There are only 4 cases of rudimentary meningocele with such a connection reported in the literature -2 in the cervical ${ }^{1,6}$ and 2 in the lumbar $^{1,7}$ region - but all of them were in infants and represented only inconspicuous fibrous tracts plus a small osseous defect or none at all.

Most of the recent literature concerned with this entity concluded that this entity is a form of a dysraphism and remnant of a neural tube defect which is believed to be nonneplastic. $^{1,6}$
In variance with the literature, we noted an unusual location of this entity i.e. thoracic; as well as a focus of neuroglial tissue and termed it "rudimentary myelomeningocele". Intraspinal communication could not be detected intra-operatively and no postoperative complication was noticed.

\section{CONCLUSION}

We believe this is the first reported case of a rudimentary myelomeningocele in the thoracic region and consider it as non-neoplastic lesion. In light of the probable pathogenesis, imaging studies to exclude any communication to the central nervous system should precede any invasive evaluation or intervention.

\section{REFERENCES}

1. El Shabrawi-Caelen L, White WL, Soyer HP, Kim BS, Frieden IJ, McCalmont TH. Rudimentary meningocele: remnant of a neural tube defect? Arch Dermatol. 2001;137:45-50.

2. Lopez DA, Silvers DN, Helwig EB. Cutaneous meningioma: a clinicopathologic study. Cancer. 1974;34:728-44.

3. Sibley DA, Cooper PH. Rudimentary meningocele: a variant of "primary cutaneous meningioma." J Cutan Pathol. 1989;16:72-80.

4. Suster S, Rosai J Hamartoma of the scalp with ectopic meningothelial elements: a distinctive benign soft tissue lesion that may simulate angiosarcoma. Am J Surg Pathol. 1990;14:111.

5. Winkler $M$ Über Psammome der Haut und des Unterhautgewebes. Arch Pathol Anat. 1904;178:322-50.

6. Hao W, Wenhua Y, Zhang Z, Lu Y, Li X. Cervical rudimentary meningocele in adulthood: Case report. Journal of Neurosurgery: Spine. 2013;18:511-4.

7. Zaaroor M, Borovich B, Bassan L, Doron Y, Gruszkiewicz J. Primary cutaneous extravertebral meningioma: case report. J Neurosurg. 1984;60:1097-8. 